\title{
Mental Strength and Challenges among Thai Medical Students in Their Clinical Years-Study Protocol
}

\author{
Tanrin Hiranwong ${ }^{1,+}{ }^{,}$, Patipan Sitthiprawiat ${ }^{1,+}$, Sirinut Siritikul ${ }^{1}$, Jiraphat Jiwtrakul ${ }^{1}$, Sirilux Klaychaiya ${ }^{1}$, \\ Pookit Chaipinchana ${ }^{1}$, Pimolpun Kuntawong ${ }^{2}$, Tinakon Wongpakaran ${ }^{2, *}$, Nahathai Wongpakaran ${ }^{2}$, \\ Athavudh Deesomchok ${ }^{1}$ and Danny Wedding ${ }^{3}$
}

Citation: Hiranwong, T.; Sitthiprawiat, P.; Siritikul, S.; Jiwtrakul, J.; Klaychaiya, S.; Chaipinchana, P.; Kuntawong, P.; Wongpakaran, T.; Wongpakaran, N.; Deesomchok, A.; et al. Mental Strength and Challenges among Thai Medical Students in Their Clinical Years-Study Protocol. Healthcare 2021, 9, 305. https://doi.org/ 10.3390/healthcare9030305

Academic Editor: Pedram Sendi

Received: 9 February 2021

Accepted: 7 March 2021

Published: 10 March 2021

Publisher's Note: MDPI stays neutral with regard to jurisdictional claims in published maps and institutional affiliations.

Copyright: (c) 2021 by the authors. Licensee MDPI, Basel, Switzerland. This article is an open access article distributed under the terms and conditions of the Creative Commons Attribution (CC BY) license (https:// creativecommons.org/licenses/by/ $4.0 /)$.
1 Faculty of Medicine, Chiang Mai University, 110 Intawaroros Rd., T. Sriphum, A. Muang, Chiang Mai 50200, Thailand; tanrin_h@cmu.ac.th (T.H.); patipan_s@cmu.ac.th (P.S.); sirinut_siritikul@cmu.ac.th (S.S.); jiraphat_j@cmu.ac.th (J.J.); sirilux_klaychaiya@cmu.ac.th (S.K.); pookitpun@gmail.com (P.C.); athavudh.d@cmu.ac.th (A.D.)

2 Department of Psychiatry, Faculty of Medicine, Chiang Mai University, 110 Intawaroros Rd., T. Sriphum, A. Muang, Chiang Mai 50200, Thailand; pimolpun_k@cmu.ac.th (P.K.); nahathai.wongpakaran@cmu.ac.th (N.W.)

3 Saybrook University, Pasadena, CA 91103, USA; danny.wedding@gmail.com

* Correspondence: tinakon.w@cmu.ac.th; Tel.: +66-53-935422 (ext. 320); Fax: +66-53-935426

$\dagger$ These authors are equally first authored.

Abstract: (1) Background: Mental well-being and mental health problems are both important, especially among medical students who will be future doctors. The proposed study aimed to explore both positive and negative mental health experiences, especially mistreatment, occurring among medical students in their clinical years. (2) Methods/design: The study will conduct a crosssectional survey between January 2021 and December 2021, among medical students studying in their clinical years across 23 medical schools throughout Thailand. Measurements regarding character strengths related to medical professionalism as well as other positive mental health strengths and negative mental health problems, e.g., anxiety, depression and experience of mistreatment will be completed. Both medical students and faculty members will be invited to participate in the study. (3) Discussion: this survey will provide an overall picture of medical students' mental well-being, positive and negative aspects of mental health and the magnitude of mistreatment and perspectives they experience. The limitations of the survey will be discussed.

Keywords: well-being; mistreatment; mental health; character strength; medical students; clinical

\section{Introduction}

Ensuring medical students' psychological, social and physical well-being is an ongoing concern for any medical school, and in many ways these factors are as important as academic achievement. A systemic review revealed that the estimated prevalence of depression or depressive symptoms among medical students reached $27.2 \%$, and suicidal ideation was $11.1 \%$ [1,2]. In Thailand, another study showed that $30 \%$ of medical students were clinically depressed, while $12 \%$ had suicidal ideation [3]. We intended to develop a program aimed to optimize not only academic achievement but also professionalism and student well-being [4,5]. Many factors are related to medical students' academic achievement, mental health problems and well-being. At the individual level, personal strengths and perceived social supports played important roles in motivation for studying, mental health and well-being [6,7].

Well-being is an elusive term, rooted in the concepts of hedonia (pleasure-seeking) and Eudaimonia (a contented state of being happy, healthy and prosperous). Hedonia consists of two components: life satisfaction and the balance between positive and negative affects [8,9], while eudaimonia describes a broad type of well-being. When investigating the measurements using the two concepts, no discriminant validity has been found. 
However, researchers are encouraged to evaluate and investigate specific variables, e.g., character strengths, rather than hedonia and eudaimonia [10]. Some medical educators have adopted Dodge et al.'s recommendation in defining well-being, quoted as, "when individuals have the psychological, social and physical resources they need to meet a particular psychological, social and/or physical challenge" [11]. For example, when individuals have sufficient resilience, they can cope with stress, symptoms of anxiety or depression and burnout [4]. Well-being is also proposed in six components which are purpose in life, environmental mastery, positive relationships, personal growth, autonomy and self-acceptance [12]. Although factors that affect the well-being may vary according to cultural influences, personality or social background $[8,13]$, the six core values remain the same. Well-being is not a stable state. Studies have strived to find ways to achieve a sustainable change of happiness or well-being. Diener, Lyubomirsky and colleagues $[8,14]$ found that happiness or well-being is regulated by genetics influencing the set point of well-being, e.g., personality trait and intentional activity, practicing positive "virtues", e.g., gratitude and happiness-relevant circumstantial factors, e.g., childhood trauma.

Medical students may have different ways of developing and sustaining their sense of well-being compared with people in general. Being accepted as a medical student may be the first time one feels a boost to their sense of well-being. Medical students not only need to succeed academically but need to learn and internalize positive psychological attributes to become a competent doctor. Another time that boosts their sense of wellbeing is when they encounter a real patient in the 4th year. However, becoming a junior student surrounded by senior students and experienced doctors could result in emotional stress. Studies showed that medical students' well-being was associated not only with their perceptions of supportive learning environments but also with empathy, moral reasoning and tolerance of uncertainty that they possess [15].

Related research supports that medical students experience higher stress levels, higher rates of burnout, poorer quality of life, depressive symptoms and suicidal ideation more than young adults $[16,17]$.

Character strengths are related to academic achievement, mental health problems and well-being. They are related to medical professionalism including self-regulation, an ability to control one's emotions [18]; gratitude, a thankful feeling and/or appreciation [19]; prudence, thoughtful, logical thinking, and the ability to plan methods to achieve goals [18]; humility, defined as a state of mind that is humble or free from arrogance [18]; and resilience, referring to a process of adapting well when facing stressors such as trauma, tragedy or threats. Employing these character strengths increases happiness [20] and enhances positive feelings resulting in a greater overall sense of well-being [19]. Further, these characteristics enhance positive relationships with patients, improve clinical outcomes [19] and are associated with well-being, stress coping, low rate of burnout, a reduced sense of victimization and improvements in medical students' mental health [21-25]. Moreover, feeling supported by family members, friends or significant others helps to reduce stress and mental problems and enhances positive mental health and self-esteem [26].

Apart from the individual level, the institutional level is also important. Mental health and well-being of medical students can be supported by a variety of methods such as extracurricular activities that promote character strength and well-being. Medical schools can provide supportive environments that promote students' personal growth while difficulties or distress can be safely addressed and managed to improve medical students' mental well-being [27].

Despite these efforts, medical students still experience mental health difficulties. Relationships with peers and colleagues play an important role and directly affect medical students' psychological state. Study in the clinical years (four to six) inevitably involves difficult encounters with numerous people including residents and senior faculty. These encounters allow students the opportunity to acquire knowledge and develop the attributes of a competent physician; on the other hand, they can also lead to the potential for being mistreated. Mistreatment is defined as "either intentional or unintentional acts occurring 
when behavior shows disrespect for the dignity of others and unreasonably interferes with the learning process." Mistreatment can include sexual harassment; discrimination or harassment based on race, religion, ethnicity, sex, or sexual orientation; humiliation; psychological or physical punishment; and the use of grading and other forms of assessment in a punitive manner [28]. Mistreatment has been reported among 4 to $41 \%$ of students across medical schools. The most common form of mistreatment was public humiliation from clinical professors [28].

Problems like these can arise in any society but are somewhat less likely in a highly structured environment such as a medical school. However, being mistreated can affect academic performance $[29,30]$, and some students respond to mistreatment with stress, burnout, anxiety, depression and decreased motivation to continue studying [31-34]. Other problems include the inability to provide high quality of care to patients, personal shame and doubt, relationship problems or substance misuse and suicide [33,35,36] (Figure 1). To what extent mistreatment affects medical students' quality of life remains unknown.

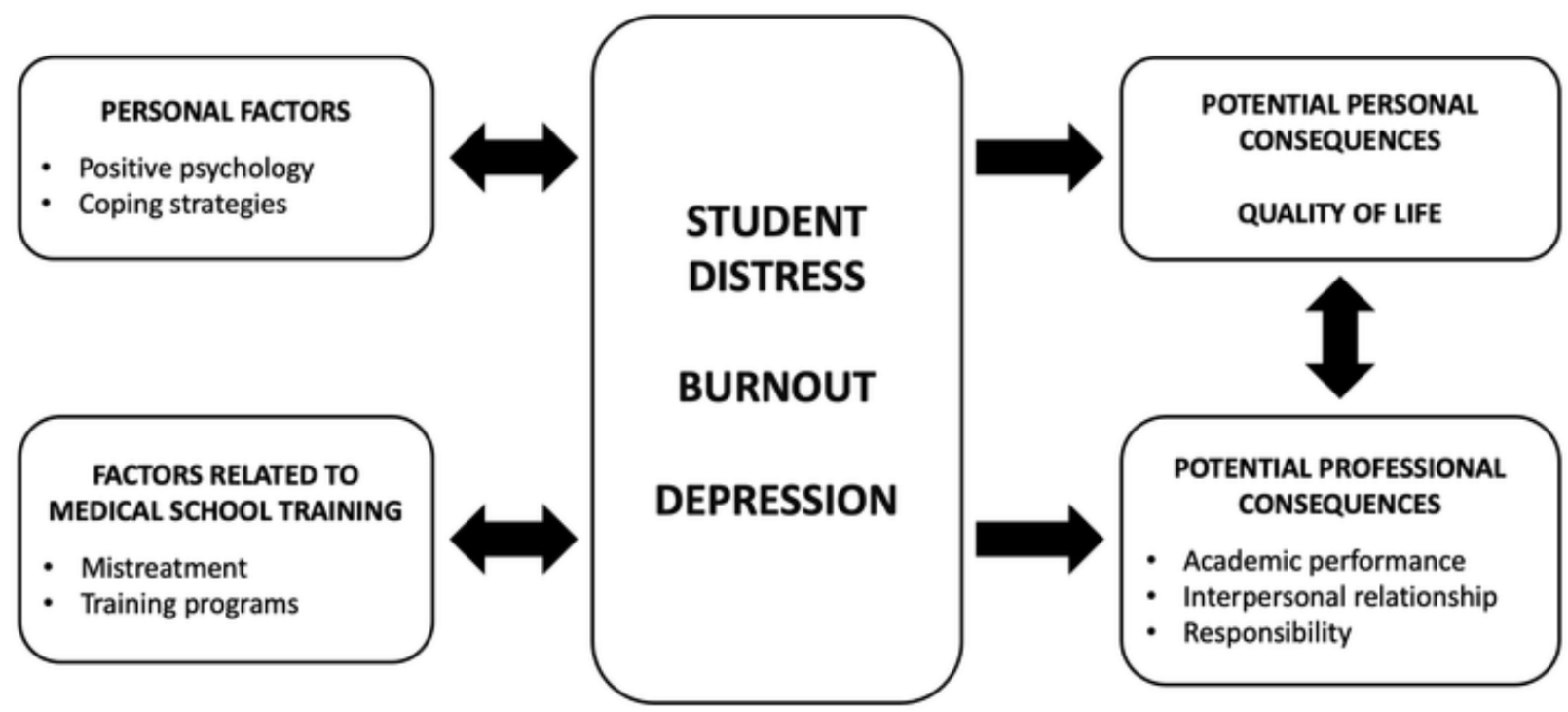

Figure 1. Relationship between student distress, personal factors, potential personal consequences and factors related to medical school training.

Mistreatment can be expressed in a variety of forms, and societal and cultural factors may be involved. Some mistreatment behaviors may be viewed or interpreted differently by other cultures and those who are involved with mistreatment $[37,38]$. Sadly, the number of reports of mistreatment among medical students seems to be growing across cultures $[31,32,34]$.

Although mistreatment remains a challenging issue in medical education, problems are preventable with appropriate communication and a clear understanding between medical personnel and students [33,35,39]. However, several studies have shown that managing systems to eliminate such problems remains ineffective and unsafe [28,32]. In contrast, cultivating positive psychology attributes can reduce rates of depression and increase positive aspects of medical school and cultivate a sense of well-being [40-42]. Whether positive virtues or character strengths can buffer or prevent the negative psychological consequences after mistreatment remains unknown.

\section{Current Study}

This study proposed to promote medical students' academic performance, mental health and quality of life. We aimed to determine those factors that either positively or negatively affect medical students. The study aimed to explore character strengths among medical students, especially those related to medical professionalism, as well as 
any mistreatment experiences, all of which are related to their psychological well-being. In addition, students' mental health status and quality of life were explored. Because faculty members may be involved in medical student mistreatment, investigating this issue was crucial $[31,37,38,43]$. In this study, the authors asked instructors and faculty members to participate to examine their perspectives on mistreatment as well as their own mental health and quality of life.

Based on aforementioned studies, we hypothesized that medical students would experience mental health problems, e.g., perceived stress, depression and anxiety the same as nonmedical undergraduate students in the university. We expected the medical student to have high levels of character strength, motivation, perceived social support, psychological well-being and quality of life. We expected to discover some mistreatment incidence and hoped to obtain some useful information related to that incidence, e.g., supporting system. We hypothesized that students' strength would reduce or become a buffer against stress and psychological problems.

\section{Materials and Methods}

\subsection{Study Design and Time-Period}

The study will employ a cross-sectional design among medical students and faculty members currently studying and working in 23 qualified medical schools throughout Thailand (12 December 2019).

\subsection{Study Population}

The participants will be medical students currently studying in their clinical years, years 4 to 6 . Inclusion criteria include students having (1) an electronic device with an internet connection such as mobile phone, tablet or personal computer to submit questionnaires and (2) they will have passed at least one rotation in clinical training. For instructors, the criteria include (1) currently working within one of the 23 certified Thai medical schools, (2) having at least 1 year of teaching experience in clinical training and (3) possessing an electronic device with internet connection such as mobile phone, tablet or personal computer to submit questionnaires.

\subsection{Procedure and Participant Invitation}

Because of COVID-19 pandemic requirements for physical distancing, we developed an online questionnaire for this study. The investigator team will provide the relevant link or the Quick Response code (QR code) to all potential participants. Flyers to invite students to participate in the study will be placed in private areas such as medical students' dormitories or private rooms for medical students in teaching hospitals. Social media networks such as LINE and medical student associations will be used to communicate and distribute the questionnaires. A convenience and snowball sampling strategy will be applied to recruit potential participants. No reimbursement, gifts or payments will be offered to compensate for completing the questionnaires.

Data will be collected for one year. Information regarding informed consent and details about the study will be included on the first page of the questionnaire before participants answer questions to ensure that participants understand and willingly participate in the study. Personal details that could be used to identify respondents will be excluded from the questionnaire. More details can be found in Table 1. 
Table 1. Sociodemographic information.

\begin{tabular}{|c|c|}
\hline Demographic & Choices \\
\hline Sex & $\begin{array}{l}\text { Male } \\
\text { Female } \\
\text { Other }\end{array}$ \\
\hline Sexual orientation & $\begin{array}{l}\text { Homosexual } \\
\text { Heterosexual } \\
\text { Bisexual } \\
\text { Others }\end{array}$ \\
\hline Age & 22 to 24 years old \\
\hline Physical disease & $\begin{array}{l}\text { Hypertension } \\
\text { Diabetes } \\
\text { Hyperlipidemia } \\
\text { Hyperthyroidism } \\
\text { Asthma } \\
\text { Others } \\
\text { None }\end{array}$ \\
\hline Mental health problem & $\begin{array}{l}\text { Depressive disorder } \\
\text { Persistent depressive disorder } \\
\text { Anxiety Disorder } \\
\text { Obsessive Compulsive Disorder } \\
\text { Bipolar disorder } \\
\text { Others }\end{array}$ \\
\hline Religion & $\begin{array}{l}\text { Buddhism } \\
\text { Christianity } \\
\text { Islam } \\
\text { None } \\
\text { Others }\end{array}$ \\
\hline Current habitat & $\begin{array}{l}\text { House } \\
\text { Faculty dormitory } \\
\text { General dormitory } \\
\text { Renting house } \\
\text { Others }\end{array}$ \\
\hline Whom do you live with? & $\begin{array}{l}\text { Family member } \\
\text { Roommate } \\
\text { No one }\end{array}$ \\
\hline Monthly income (THB) & $\begin{array}{l}\text { Less than } 5000 \\
5000-10,000 \\
10,000-15,000 \\
\text { More than } 15,000\end{array}$ \\
\hline $\begin{array}{l}\text { Ward/Department on your rotation at the } \\
\text { present }\end{array}$ & $\begin{array}{l}\text { e.g., Medicine, Surgery, Pediatrics, Obstetric and } \\
\text { Gynecology }\end{array}$ \\
\hline Ward/Department you have been to & $\begin{array}{l}\text { e.g., Medicine, Surgery, Pediatrics, Obstetric and } \\
\text { Gynecology }\end{array}$ \\
\hline Grade Point Average (GPA) & \\
\hline
\end{tabular}

\subsection{Measurements}

All individuals will complete the surveys on their own. The primary questionnaires will include sociodemographic data, information related to participants' status, information related to support and extracurricular activities provided by the faculty, followed by questionnaires assessing positive qualities including the Resilient Inventory (RI-9) measuring the extent to which individuals feel confident to overcome difficulties in life [44]. In addition, PhuSeG scale, a 10-item composite scale assessing prudence, humility, selfregulation and gratitude [45], Thai version Rosenberg Self-Esteem Scale (RSES) measuring 
global self-worth including both positive and negative feelings about the self [46] and the Revised Thai Multidimensional Scale of Perceived Social Support (rMSPSS), measuring the extent to which an individual feels support by family members, friends and significant others will also be used $[47,48]$. The Academic Motivation Scale (AMS) assessing three types of motivation based on the self-determination theory, i.e., intrinsic, extrinsic and amotivation [49], Thai version of the Perceived Stress Scale (T-PSS-10) measuring the extent to which individuals perceived stress [50] and EQ-5D used for quality of life scoring [51] will also be included. In addition, a visual analog of Burnout scale, a single-item measure of burnout ranging from 0 to 100, Core Symptom Index (CSI-15) designed to measure anxiety, depression and somatization symptoms [52] and Traumatic Experience Scale (TES) addressing potentially traumatizing events will be employed. The items include emotional neglect, emotional abuse and physical abuse from family members, and they were developed by T. Wongpakaran and N. Wongpakaran. The instrument uses a 5-point Likert scale, ranging from 1 (never) to 5 (almost always). The score ranges from 25 to 125, the higher the score the higher the level of traumatic experience. Preliminary findings suggested that the TES is a reliable and valid self-report instrument that can be used in clinical practice and research (Cronbach $\alpha=0.91)$. Lastly, Mistreatment Questionnaires will investigate the participants' experiencing or witnessing an episode of mistreatment. More details can be found in Table 2.

\subsection{Statistical Analysis Plan}

\subsubsection{Sample Size Calculation}

The minimal numbers of required participants for the cross-sectional study was calculated using a formula developed by Jaykaran Charan and Tamoghna Biswas [53]. A related study conducted at a Thai medical school in the southern region [31] indicated that the proportion of medical students experiencing mistreatment at least once during their clinical years totaled $63.4 \%$. With the absolute error of $5 \%(\mathrm{~d}=0.05)$ and type I error at $5 \%(Z=1.96)$, we calculated the numbers of required participants; these calculations indicated we needed to recruit at least 357 participants for this study. As related research has not provided estimates of the proportion of medical professors mistreating medical students compared with all medical professors, we assume that the proportion is 0.5 ; therefore, we will need to recruit at least 385 medical professors to participate in this study. However, because we are using an online survey method, we do not anticipate any difficulty recruiting subjects. In this study, the participants do not receive any remuneration.

\subsubsection{Statistical Analysis}

Descriptive statistics will be used for sociodemographic data presented as frequency; percentage (\%) will be used for categorical variables, e.g., sex, while continuous variables, e.g., age and resilience inventory score, will be presented as mean \pm standard deviation or median (min-max). To assess differences between groups, chi-square, $t$-test, and ANOVA will be used. Correlation and regression will be used to examine associations between anticipated outcomes and predictors. $p$-values $<0.05$ will be considered significant correlations. STATA, Version 13.0, and SPSS, 22.0 will be used for data cleaning and statistical analysis. Multiple imputations will be used for missing data or incomplete responses. 
Table 2. Measurement tools of the survey.

\begin{tabular}{|c|c|c|c|c|c|}
\hline Instrument & Aim in Assessing & Response Format & Number of Items & Recall Period & Internal Consistency \\
\hline Resilient Inventory (RI-9) & Level of resiliency & 5 & 9 & Current & 0.88 \\
\hline PhuSeG scale & Level of character strength & 5 & 10 & Current & 0.89 \\
\hline $\begin{array}{l}\text { Revised Thai Multidimensional Scale of Perceived } \\
\text { Social Support (rMSPSS) }\end{array}$ & Level of perceived social support & 7 & 12 & Current & 0.91 \\
\hline Academic Motivation Scale (AMS) & Level of motivation and amotivation & 7 & 28 & Past to present & 0.84 \\
\hline$E Q-5 D$ & Quality of life & 5 & 5 & Current & 0.87 \\
\hline A visual analog of Burnout scale & Level of burnout & 10 & 1 & Current & $1.00(\mathrm{CVI})$ \\
\hline Core Symptom Index (CSI-15) & Severity of psychological distress & 5 & 15 & Past 1 week & 0.85 \\
\hline Traumatic Experience Scale (TES) & Level of childhood traumatic experience & 5 & 25 & Childhood & 0.91 \\
\hline Composite Questionnaire of Mistreatment & $\begin{array}{l}\text { Qualitative and quantitative data of } \\
\text { mistreatment experience }\end{array}$ & mixed & 13 & Past to present & $1.00(\mathrm{CVI})$ \\
\hline
\end{tabular}

Internal consistency is calculated using Cronbach's alpha coefficient ( $>0.7$ considered acceptable); $C V I=$ content validity index ( $>0.8$ considered acceptable). 


\subsection{Ethics Approval, Consent to Participate, Autonomy and Confidentiality}

The study has been approved by the Ethics Committee of the Faculty of Medicine, Chiang Mai University. The invitation process will be conducted without inducement or coercion. Students who volunteer to participate in this study will submit anonymous self-reported questionnaires, and the research will be entitled, "Educational experience in clinical years in Thai medical schools" to avoid leading questions that result in biased responses. Individual identification will not be required to ensure participants' anonymity and safety. Neither participant identification data nor university name will be mentioned in any report or publication. Communication between researchers and participants will be conducted by assigned representatives in each university using contact numbers and the email address of the researchers. A written informed consent embedded on the first page of the online questionnaire will have to be signed electronically before anyone completes the questionnaires. When participants respond ' $\mathrm{No}^{\prime}$ " to this question, it will be deemed a refusal to participate, and the process will be ended. At the conclusion of each questionnaire, advice regarding safety issues, e.g., coping with suicidal ideation, will be provided, and students will be told where they can go and what they can do to seek help. All participants can leave any item(s) unanswered if they feel uncomfortable responding to the item(s).

\section{Discussion}

This study constitutes the first nationwide evaluation of mental health, character strength, mental health problems, mistreatment and quality of life among medical students completing their clinical years in Thailand. Assessing the mental health of medical students is important to ascertain how well they are prepared to enter a highly demanding profession like medicine. Psychological well-being is important for medical students, and they also need to learn how to maintain this state. In addition, medical students have to learn to balance competing needs. For example, on the one hand, medical students need to develop interpersonal sensitivity and be attuned to patient's emotions [54]; on the other hand, they may easily burnout as a result of such sensitivity [55]. As noted earlier, psychological wellbeing can be temporary according to the concept of the hedonic treadmill which suggests that any gains in happiness or well-being are only temporary, because humans so quickly adapt to change. Based on Lyubomirsky et al., to create sustainable well-being, students may need to work on promoting intentional or activity-related character strengths such as gratitude, resilience and self-regulation. This could promote the enjoyment of positive life experiences so that life satisfaction and enjoyment are extracted from one's circumstances such as childhood trauma [14]. At the same time, negative affects derived from the past childhood trauma and current mistreatment need to be tackled. Well-being is not unitary but involves multidimensional aspects and concepts also have a number of implications [8]. This study will provide information regarding the potential strengths and weaknesses of the students we investigate, which would be useful for any further interventions.

The study will also reveal psychological features that could be related to variables such as self-esteem or motivation for studying medicine. Study findings also can be compared with those of medical students in other countries. The same is true with some character strengths, perceived stress and perceived social support, all of which have been shown to be related to student well-being and clinical performance.

We intend to ask participants about their childhood traumatic experiences. This information will provide insights about vulnerability to stress or mistreatment. More importantly, we are curious to determine whether early traumatic experiences would be related to students' mental health difficulties and well-being. One study showed the direct relationship between childhood trauma and school bullying victimization [56]. However, evidence on the correlation between childhood trauma and mistreatment, regardless of being a person who is mistreated or who mistreats, is scarce. When a relationship is identified, it may be possible to identify and implement an intervention to prevent or reduce the influence of the history of mistreatment. 
Another important issue related to childhood traumatic experience is unstable personality traits [57]. Recent findings have shown that university students have a high prevalence of unstable personality conditions such as borderline personality disorder [58,59]. Such an unstable personality could easily lead to mental health problems and affect psychological well-being. Only a few studies have investigated this important issue among medical students [60]. Our study will provide an opportunity to explore these relationships. For example, we will be interested in examining whether resilience influences the link between mistreatment and anxiety or depressive symptoms. We also hope to understand whether perceived social support plays a role in increasing self-esteem when students experience mistreatment.

In addition, the study will provide us insights concerning how well the students perceive happiness-relevant activities provided by the faculty through extracurricular activities [14], particularly, how much access and help they receive in times of need, e.g., when they are depressed or mistreated.

Some limitations of the proposed research are, firstly, the study employs a crosssectional design, and this will preclude any examination of causal relationships. However, this initial study will set the stage for further and deeper studies in the future. Secondly, personality traits that are related to both negative mental health problems and psychological well-being [14] will not be included in this study.

\section{Conclusions}

This cross-sectional study will provide a snapshot of strengths and weaknesses, both at individual and institutional levels. It will alert those involved in the process to recognize the well-being medical students possess, how much difficulty they experience psychologically, the extent and magnitude of the ongoing problem of mistreatment and what factors are involved. All these data will provide insights to help us clearly plan the next steps in enhancing medical students' well-being in Thailand.

Author Contributions: Conceptualization, T.H., P.S., S.S., J.J., S.K., P.C., A.D., P.K., T.W., N.W., and D.W.; methodology, T.H., P.S., T.W., and N.W.; software, T.H., T.W., and N.W.; validation, S.S., J.J., S.K., P.C., A.D., and D.W.; formal analysis, T.H., P.S., and T.W.; investigation, A.D., P.K., and D.W.; resources, A.D. and P.K.; data curation, P.K.; writing-original draft preparation, T.H., P.S., S.S., J.J., S.K., P.C., A.D., P.K., T.W., N.W., and D.W.; writing-review and editing, T.H., P.S., S.S., J.J., S.K., P.C., T.W., N.W., and D.W.; visualization, S.S., J.J., S.K., and P.C.; supervision, T.W., N.W., and D.W.; project administration, T.H. and T.W.; funding acquisition, T.H., T.W., and N.W. All authors read and approved the final manuscript.

Funding: This research was supported by the Research Medical Fund, Grant Number 40/2564, Faculty of Medicine, Chiang Mai University. The funder had no role in study design, data collection and analysis, decision to publish, or preparation of the manuscript.

Institutional Review Board Statement: The study was conducted according to the guidelines of the Declaration of Helsinki, and approved by the Institutional Review Board (or Ethics Committee) of Faculty of Medicine, Chiang Mai University (protocol code REC-25630813-20680 and date of approval: 30 October 2020).

Informed Consent Statement: All patients provided written informed consent to the study.

Conflicts of Interest: The authors declare that they have no competing interests.

\section{References}

1. Karp, J.F.; Levine, A.S. Mental Health Services for Medical Students-Time to Act. N. Engl. J. Med. 2018, 379, 1196-1198. [CrossRef] [PubMed]

2. Rotenstein, L.S.; Ramos, M.A.; Torre, M.; Segal, J.B.; Peluso, M.J.; Guille, C.; Sen, S.; Mata, D.A. Prevalence of Depression, Depressive Symptoms, and Suicidal Ideation Among Medical Students: A Systematic Review and Meta-Analysis. JAMA 2016, 316, 2214-2236. [CrossRef] 
3. Kolkijkovin, V.; Phutathum, S.; Natetaweewat, N.; Joodthong, P.; Phaisanwongdee, P.; Nateetaweewat, P.; Jantarawattanawanich, A. Prevalence and Associated Factors of Depression in Medical Students at Faculty of Medicine Vajira Hospital, Urban University. J. Med. Assoc. Thail. 2019, 102, 5.

4. Kemp, S.; Hu, W.; Bishop, J.; Forrest, K.; Hudson, J.N.; Wilson, I.; Teodorczuk, A.; Rogers, G.D.; Roberts, C.; Wearn, A. Medical student wellbeing-A consensus statement from Australia and New Zealand. BMC Med. Educ. 2019, 19, 69. [CrossRef] [PubMed]

5. Rafique, M.; Nuzhat, A.; Enani, M.A. Professionalism in Medical Education-Perspectives of Medical Students and Faculty. Med. Ed. Publ. 2017, 6. [CrossRef]

6. Heinen, I.; Bullinger, M.; Kocalevent, R.D. Perceived stress in first year medical students-Associations with personal resources and emotional distress. BMC Med. Educ. 2017, 17, 4. [CrossRef]

7. Kunanitthaworn, N.; Wongpakaran, T.; Wongpakaran, N.; Paiboonsithiwong, S.; Songtrijuck, N.; Kuntawong, P.; Wedding, D. Factors associated with motivation in medical education: A path analysis. BMC Med. Educ. 2018, 18, 140. [CrossRef]

8. Diener, E.; Heintzelman, S.J.; Kushlev, K.; Tay, L.; Wirtz, D.; Lutes, L.D.; Oishi, S. Findings all psychologists should know from the new science on subjective well-being. Can. Psychol. Psychol. Can. 2017, 58, 87-104. [CrossRef]

9. Busseri, M.A.; Sadava, S.W. A review of the tripartite structure of subjective well-being: Implications for conceptualization, operationalization, analysis, and synthesis. Personal. Soc. Psychol. Rev. 2011, 15, 290-314. [CrossRef]

10. Disabato, D.J.; Goodman, F.R.; Kashdan, T.B.; Short, J.L.; Jarden, A. Different types of well-being? A cross-cultural examination of hedonic and eudaimonic well-being. Psychol. Assess. 2016, 28, 471-482. [CrossRef]

11. Dodge, R.; Daly, A.P.; Huyton, J.; Sanders, L.D. The challenge of defining wellbeing. Int. J. Wellbeing 2012, 3, 222-235. [CrossRef]

12. Ryff, C.D. Psychological well-being revisited: Advances in the science and practice of eudaimonia. Psychother. Psychosom. 2014, 83, 10-28. [CrossRef]

13. Rzeszutek, M.; Gruszczyńska, E.; Firlag-Burkacka, E. Socio-Medical and Personality Correlates of Psychological Well-Being among People Living with HIV: A Latent Profile Analysis. Appl. Res. Qual. Life 2019, 14, 1113-1127. [CrossRef]

14. Lyubomirsky, S.; Sheldon, K.M.; Schkade, D. Pursuing Happiness: The Architecture of Sustainable Change. Rev. Gen. Psychol. 2005, 9, 111-131. [CrossRef]

15. Benbassat, J. Changes in wellbeing and professional values among medical undergraduate students: A narrative review of the literature. Adv. Health Sci. Educ. Theory Pract. 2014, 19, 597-610. [CrossRef] [PubMed]

16. Chattu, V.K.; Sahu, P.K.; Seedial, N.; Seecharan, G.; Seepersad, A.; Seunarine, M.; Sieunarine, S.; Seymour, K.; Simboo, S.; Singh, A. Subjective Well-Being and Its Relation to Academic Performance among Students in Medicine, Dentistry, and Other Health Professions. Educ. Sci. 2020, 10, 224. [CrossRef]

17. Dyrbye, L.N.; Harper, W.; Durning, S.J.; Moutier, C.; Thomas, M.R.; Massie, F.S., Jr.; Eacker, A.; Power, D.V.; Szydlo, D.W.; Sloan, J.A.; et al. Patterns of distress in US medical students. Med. Teach. 2011, 33, 834-839. [CrossRef]

18. Niemiec, R.M.; Wedding, D. Positive Psychology at the Movies: Using Films to Build. Virtues and Character Strengths; Hogrefe Publishing: Göttingen, Germany, 2013.

19. Sansone, R.A.; Sansone, L.A. Gratitude and well being: The benefits of appreciation. Psychiatry 2010, 7, 18-22. [PubMed]

20. Morton, D.P. Combining Lifestyle Medicine and Positive Psychology to Improve Mental Health and Emotional Well-being. Am. J. Lifestyle Med. 2018, 12, 370-374. [CrossRef] [PubMed]

21. Thompson, G.; McBride, R.B.; Hosford, C.C.; Halaas, G. Resilience Among Medical Students: The Role of Coping Style and Social Support. Teach. Learn. Med. 2016, 28, 174-182. [CrossRef] [PubMed]

22. Houpy, J.C.; Lee, W.W.; Woodruff, J.N.; Pincavage, A.T. Medical student resilience and stressful clinical events during clinical training. Med. Educ. Online 2017, 22, 1320187. [CrossRef] [PubMed]

23. Cooke, G.P.E.; Doust, J.A.; Steele, M.C. A survey of resilience, burnout, and tolerance of uncertainty in Australian general practice registrars. BMC Med. Educ. 2013, 13, 1-6. [CrossRef]

24. Lin, M.; Wolke, D.; Schneider, S.; Margraf, J. Bullying History and Mental Health In University Students: The Mediator Roles of Social Support, Personal Resilience, and Self-Efficacy. Front. Psychiatry 2019, 10, 960. [CrossRef]

25. Mruk, C.J. The psychology of self-esteem: A potential common ground for humanistic positive psychology and positivistic positive psychology. Humanist. Psychol. 2008, 36, 143-158. [CrossRef]

26. Lukat, J.; Margraf, J.; Lutz, R.; van der Veld, W.M.; Becker, E.S. Psychometric properties of the Positive Mental Health Scale (PMH-scale). BMC Psychol. 2016, 4, 8. [CrossRef] [PubMed]

27. Council, G.M. Supporting Medical Students with Mental Health Conditions 2015. Supporting Medical Students with Mental Health Conditions. Available online: gmc-uk.org (accessed on 1 February 2021).

28. Mavis, B.; Sousa, A.; Lipscomb, W.; Rappley, M.D. Learning about medical student mistreatment from responses to the medical school graduation questionnaire. Acad. Med. 2014, 89, 705-711. [CrossRef]

29. Oser, T.K.; Haidet, P.; Lewis, P.R.; Mauger, D.T.; Gingrich, D.L.; Leong, S.L. Frequency and negative impact of medical student mistreatment based on specialty choice: A longitudinal study. Acad. Med. 2014, 89, 755-761. [CrossRef]

30. Peres, M.F.; Babler, F.; Arakaki, J.N.; Quaresma, I.Y.; Barreto, A.D.; Silva, A.T.; Eluf-Neto, J. Mistreatment in an academic setting and medical students' perceptions about their course in Sao Paulo, Brazil: A cross-sectional study. Sao Paulo Med. J. 2016, 134, 130-137. [CrossRef]

31. Pitanupong, J.; Sathaporn, K. The Prevalence and Factors Associated with Mistreatment Perception among Thai Medical Students in a Southern Medical School. Siriraj Med. J. 2019, 71, 310-317. [CrossRef] 
32. Nagata-Kobayashi, S.; Sekimoto, M.; Koyama, H.; Yamamoto, W.; Goto, E.; Fukushima, O.; Ino, T.; Shimada, T.; Shimbo, T.; Asai, A.; et al. Medical student abuse during clinical clerkships in Japan. J. Gen. Intern. Med. 2006, 21, 212-218. [CrossRef] [PubMed]

33. Saipanish, R. Stress among medical students in a Thai medical school. Med. Teach. 2003, 25, 502-506. [CrossRef]

34. Cook, A.F.; Arora, V.M.; Rasinski, K.A.; Curlin, F.A.; Yoon, J.D. The prevalence of medical student mistreatment and its association with burnout. Acad. Med. 2014, 89, 749-754. [CrossRef]

35. Dyrbye, L.N.; Thomas, M.R.; Shanafelt, T.D. Medical student distress: Causes, consequences, and proposed solutions. Mayo Clin. Proc. 2005, 80, 1613-1622. [CrossRef]

36. Nuallaong, W. Stress in medical students of Thammasat University. Thammasat Med. J. 2010, 10, 8.

37. Olasoji, H.O. Broadening conceptions of medical student mistreatment during clinical teaching: Message from a study of "toxic" phenomenon during bedside teaching. Adv. Med. Educ. Pract. 2018, 9, 483-494. [CrossRef] [PubMed]

38. Neville, A.J. In the age of professionalism, student harassment is alive and well. Med. Educ. 2008, 42, 447-448. [CrossRef] [PubMed]

39. Lind, K.T.; Osborne, C.M.; Badesch, B.; Blood, A.; Lowenstein, S.R. Ending student mistreatment: Early successes and continuing challenges. Med. Educ. Online 2020, 25, 1690846. [CrossRef] [PubMed]

40. Lee, R.S.; Oswald, L.M.; Wand, G.S. Early Life Stress as a Predictor of Co-Occurring Alcohol Use Disorder and Post-Traumatic Stress Disorder. Alcohol. Res. 2018, 39, 147-159.

41. Pynoos, R.S.; Steinberg, A.M.; Piacentini, J.C. A developmental psychopathology model of childhood traumatic stress and intersection with anxiety disorders. Biol. Psychiatry 1999, 46, 1542-1554. [CrossRef]

42. Schrank, B.; Brownell, T.; Tylee, A.; Slade, M. Positive psychology: An approach to supporting recovery in mental illness. East. Asian Arch. Psychiatry 2014, 24, 95-103.

43. Baldwin, D.C., Jr.; Daugherty, S.R.; Eckenfels, E.J. Student perceptions of mistreatment and harassment during medical school. A survey of ten United States schools. West. J. Med. 1991, 155, 140-145.

44. Wongpakaran, N.; Wongpakaran, T. Resilience Inventory. 2020. Resilient Inventory RI-9 Eng.pdf. Available online: pakaranhome. com (accessed on 20 January 2021).

45. Siritikul, S.; Chalanunt, S.; Utrapiromsook, C.; Mungara, S.; Wongpakaran, T.; Wongpakaran, N.; Kuntawong, P.; Wedding, D. Changes in character strengths after watching movies: When to use rasch analysis. BMC Res. Notes 2021, 14, 5. [CrossRef]

46. Wongpakaran, T.; Tinakon, W.; Wongpakaran, N.; Nahathai, W. A comparison of reliability and construct validity between the original and revised versions of the Rosenberg Self-Esteem Scale. Psychiatry Investig. 2012, 9, 54-58. [CrossRef]

47. Wongpakaran, T.; Wongpakaran, N.; Ruktrakul, R. Reliability and Validity of the Multidimensional Scale of Perceived Social Support (MSPSS): Thai Version. Clin. Pract. Epidemiol. Ment. Health 2011, 7, 161-166. [CrossRef]

48. Wongpakaran, N.; Wongpakaran, T. A revised Thai Multi-Dimensional Scale of Perceived Social Support. Span. J. Psychol. 2012, 15, 1503-1509. [CrossRef]

49. Pryse-Phillips, W.; Yorkston, N.J. Hysterical contracture complicating hemiplegia in a patient with systemic lupus erythematosus, activated in pregnancy. Guys Hosp. Rep. 1965, 114, 239-247. [PubMed]

50. Wongpakaran, N.; Wongpakaran, T. The Thai version of the PSS-10: An Investigation of its psychometric properties. Biopsychosoc. Med. 2010, 4, 6. [CrossRef] [PubMed]

51. Saipanish, R.; Lotrakul, M.; Sumrithe, S. Reliability and validity of the Thai version of the WHO-Five Well-Being Index in primary care patients. Psychiatry Clin. Neurosci. 2009, 63, 141-146. [CrossRef] [PubMed]

52. Wongpakaran, N.; Wongpakaran, T.; Lertkachatarn, S.; Sirirak, T.; Kuntawong, P. Core Symptom Index (CSI): Testing for bifactor model and differential item functioning. Int. Psychogeriatr. 2019, 1-11. [CrossRef] [PubMed]

53. Charan, J.; Biswas, T. How to calculate sample size for different study designs in medical research? Indian J. Psychol. Med. 2013, 35, 121-126. [CrossRef]

54. Decety, J.; Batson, C.D. Social neuroscience approaches to interpersonal sensitivity. Soc. Neurosci. 2007, 2, 151-157. [CrossRef] [PubMed]

55. Bianchi, R.; Schonfeld, I.S.; Laurent, E. Interpersonal rejection sensitivity predicts burnout: A prospective study. Personal. Individ. Differ. 2015, 75, 216-219. [CrossRef]

56. Lu, L.; Jian, S.; Dong, M.; Gao, J.; Zhang, T.; Chen, X.; Zhang, Y.; Shen, H.; Chen, H.; Gai, X.; et al. Childhood trauma and suicidal ideation among Chinese university students: The mediating effect of Internet addiction and school bullying victimisation. Epidemiol. Psychiatr. Sci. 2020, 29, e152. [CrossRef] [PubMed]

57. Cipriano, A.; Cella, S.; Cotrufo, P. Nonsuicidal Self-injury: A Systematic Review. Front. Psychol. 2017, 8, 1946. [CrossRef] [PubMed]

58. Ketumarn, P.; Sitdhiraksa, N.; Sittironnarit, G.; Limsricharoen, K.; Pukrittayakamee, P.; Wannarit, K. Psychiatric Disorders and Personality Problems in Medical Students at Faculty of Medicine, Siriraj Hospital, Years 1982-2007. J. Psychiatr. Assoc. Thail. 2013, $57,427-438$.

59. Wongpakaran, N.; Wongpakaran, T. Personality disorders in medical students: Measuring by IPDE-10. J. Med. Assoc. Thai. 2005, $88,1278-1281$.

60. Sar, V.; Akyuz, G.; Kugu, N.; Ozturk, E.; Ertem-Vehid, H. Axis I dissociative disorder comorbidity in borderline personality disorder and reports of childhood trauma. J. Clin. Psychiatry 2006, 67, 1583-1590. [CrossRef] [PubMed] 